\title{
Multiple song features are related to paternal effort in common nightingales
}

\author{
Conny Bartsch ${ }^{1 *}$, Michael Weiss $^{2}$ and Silke Kipper ${ }^{1,3}$
}

\begin{abstract}
Background: Sexual ornamentation may be related to the degree of paternal care and the 'good-parent' model predicts that male secondary characters honestly advertise paternal investment. In most birds, males are involved in bringing up the young and successful reproduction highly depends on male contribution during breeding. In passerines, male song is indicative of male attributes and for few species it has been shown that song features also signal paternal investment to females. Males of nightingales Luscinia megarhynchos are famous for their elaborate singing but so far there is only little knowledge on the role of male song in intersexual communication, and it is unknown whether male song predicts male parenting abilities.

Results: Using RFID technology to record male feeding visits to the nest, we found that nightingale males substantially contribute to chick feeding. Also, we analyzed male nocturnal song with focus on song features that have been shown to signal male quality before. We found that several song features, namely measures of song complexity and song sequencing, were correlated with male feeding rates. Moreover, the combination of these song features had strong predictive power for male contribution to nestling feeding.

Conclusions: Since male nightingales are involved in chick rearing, paternal investment might be a crucial variable for female mate choice in this species. Females may assess future paternal care on the basis of song features identified in our study and thus these features may have evolved to signal direct benefits to females. Additionally we underline the importance of multiple acoustic cues for female mating decisions especially in species with complex song such as the nightingale.
\end{abstract}

Keywords: Male quality, Paternal effort, Song complexity, Song sequence, Network analysis, Song category

\section{Background}

Parental investment of the two sexes has been proposed as a key promoter of sexual selection in most species of the animal kingdom $[1,2]$. In species where both parents are involved in bringing up the young, paternal care is a crucial variable of female choice since females directly benefit from high levels of male investment [3, 4]. Biparental care is especially widespread in birds $(\sim 81 \%$ of all species, [5]) with most of the species being socially monogamous [6]. In birds, females have been found to adjust their mating strategies and their own investment according to the expected male participation in offspring rearing $[7,8]$. Females may assess paternal qualities on the basis of male secondary traits ('good-

\footnotetext{
* Correspondence: connebartsch@gmail.com

'Animal Behavior Group, Freie Universität Berlin, Takustraße 6, 14195 Berlin, Germany

Full list of author information is available at the end of the article
}

parent' model [9], but see also [10] and studies cited therein for conflicting results). Mechanisms that have been proposed to explain female assessment of male parenting abilities are similar to 'good-genes' or 'handicap' models of female choice [11]. These models assume that male extravagant traits come with costs and only males of high phenotypic and/or genetic quality manage to sustain these traits $[12,13]$. Traits that have been shown to be related to paternal qualities include morphological characteristics such as plumage coloration [14, 15] or courtship related behaviors [16-19].

In passerines, male song is such a courtship behavior [20] and there is evidence that song serves as predictor for paternal effort. For example, high song rates were found to be associated with higher feeding rates in a few species, and it was suggested that high song rates possibly indicate a male's foraging efficiency, his ability to defend a high quality territory or individual quality in 
general [21-23]. Elaborate song flights which are associated with social costs for males advertise future paternal performance in whitethroats Sylvia communis [24]. Large repertoires indicate higher feeding rates in male sedge warblers Acrocephalus schoenobaenus [25] whereas similar studies in other species failed to find a correlation between measures of song complexity and male care [22, 26-28]. Assuming that song complexity reflects a superior male status [29-31] which has been mostly linked to indirect fitness benefits for females, it might at the same time be an indicator of more direct benefits of female choice (i.e. a male's ability to provide paternal care). In summary, female songbirds may choose prospective good fathers by paying attention to male song prior to pair formation.

The common nightingale Luscinia megarhynchos is a socially monogamous passerine and from few previous observations it is known that males provide paternal care during breeding. They, for example, feed the female during incubation, provide food to nestlings and readily defend the nest against potential predators [32, 33]; CB, personal observation). Thus, reproductive success seems to be highly dependent on male contribution, making it most probable that in nightingales male parenting abilities are a crucial factor in mate choice. Furthermore, nightingales belong to the most versatile singers of the temperate zone [20]. Males have very large song repertoires of up to 250 different song types (approx. 180 different song types per male, e.g. [34, 35]) with large repertoire birds being older [36], being in better condition and arriving earlier at the breeding grounds [35]. Within repertoires, specific features of certain songs seem to carry information that might be important during different behavioral contexts, which constitutes the basis for the formation of song categories (e.g. buzz songs: [37]; trill songs: [38]; whistle songs: [39, 40]; see also Fig. 1). Furthermore, the nightingale is an excellent model to study the functional aspect of complex 'syntaxlike' rules of song delivery. Song sequencing in nightingales is neither fully fixed (e.g. singing in an A-Z manner), nor random, but instead follows sequential rules that are partly controlled by early learning and memory retrieval processes, e.g. [41-43]. However, these sequential rules are not fully deterministic, but offer potential for behavioral plasticity both short- and long-term. For example, males change their repertoire composition and song sequencing with age, which is most probably attributed to an adjustment to the breeding population [44-46], or they change the sequencing of songs in response to playbacks [47]. Also, the usage of specific song types (i.e. song categories) is related to different behavioral contexts or different times during the day and the breeding cycle, e.g. [39, 48-52] which additionally affects the sequencing of songs. Very recently it has been shown that the sequential ordering of song types is related to male attributes. For example, older males sing their songs more ordered (i.e. they sing song sequences repeatedly in the same order) and membership to a population seems to be encoded in song sequencing (i.e. members of the same population share song sequences) $[46,47]$. These findings imply that the sequential ordering of nightingale song may carry information which is relevant for females during mate choice.

If a male's song is also related to his parenting qualities, and if females use song to choose 'good fathers' has not been investigated in nightingales so far. To date, there are neither studies systematically investigating paternal care in the nightingale, nor studies looking at the relationship between song and parenting qualities. Here, we investigated the potential function of male song as an indicator for future male parental care. To do so, we analyzed paternal care by continuous recording of male provisioning behavior at the nest across several days. Also, we analyzed male nocturnal song with special focus on repertoire size, repertoire composition, and the sequencing of songs as possible candidates for the advertising function of male song. We hypothesized that males who are more committed to paternal care are "better' singers.

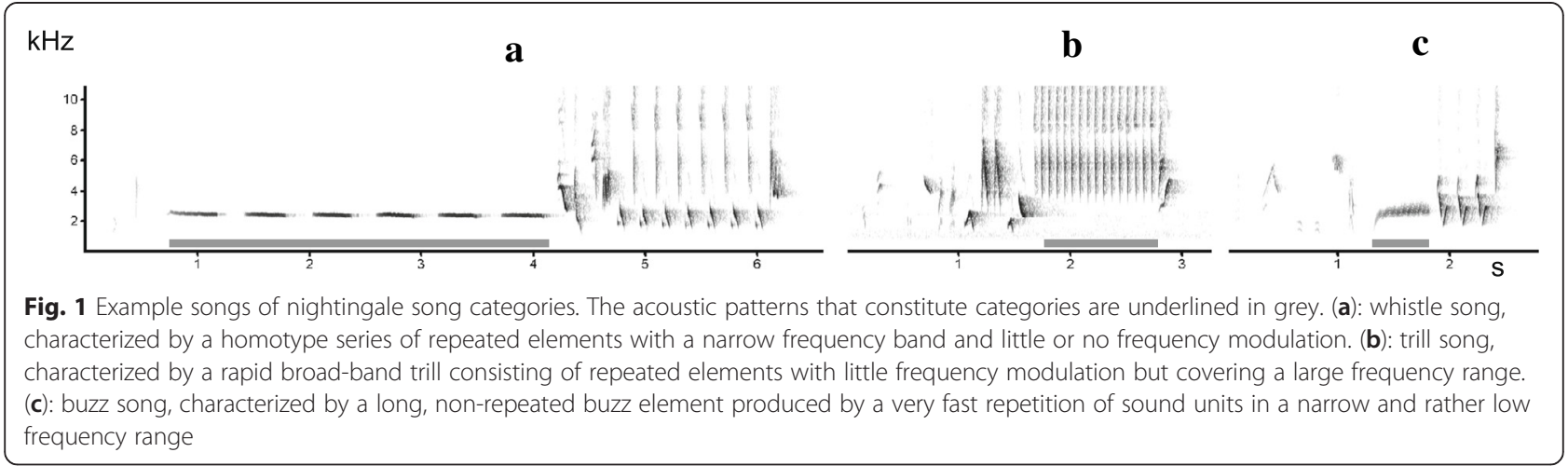




\section{Results}

Male feeding effort

The analysis of video recordings of four nests during the late nestling phase (chicks older than eight days) confirmed that male nightingales contribute to chick feeding. A comparison of the relative effort of both parents showed that males and females on average contributed equally to feeding, whereby individuals showed high variance in their feeding effort (rate [nest visits/h] males: $15.9 \pm 4.9$ (mean $\pm \mathrm{SD}$ ); rate [nest visits/h] females: $15.5 \pm 20.0$ (mean \pm SD); for details see Additional file 1: Table S1). For another 20 males, we calculated feeding rates from RFID recordings during morning and evening hours of days 5 to 12 of chick age. The feeding rate across all males was $11.4 \pm 3.8$ (mean $\pm \mathrm{SD}$ ), i.e. males on average visited the nest eleven times per hour (note that the difference in feeding rate observed in the pilot study is most probably attributed to an increase of feeding activity with nestling age (see Additional file 1: Figure S3)). Males varied considerably in their feeding behavior, whereas feeding rates were stable within males across the recording period (ANOVA, $n=20, F=12.46$, $P<0.001$; Fig. 2).

\section{Relationship between male song and feeding behavior}

First, we identified those variables with the strongest relation to male feeding rates. The LASSO algorithm resulted in four song measures: average shortest path length, buzz repertoire size, whistle repertoire size and trill repertoire size (with regression coefficients in decreasing order: $0.75,0.46,0.14$ and 0.005$)$. The four song measures were all positively correlated with male feeding rates (Spearman rank correlation, $n=20$, all $P<0.05$; see

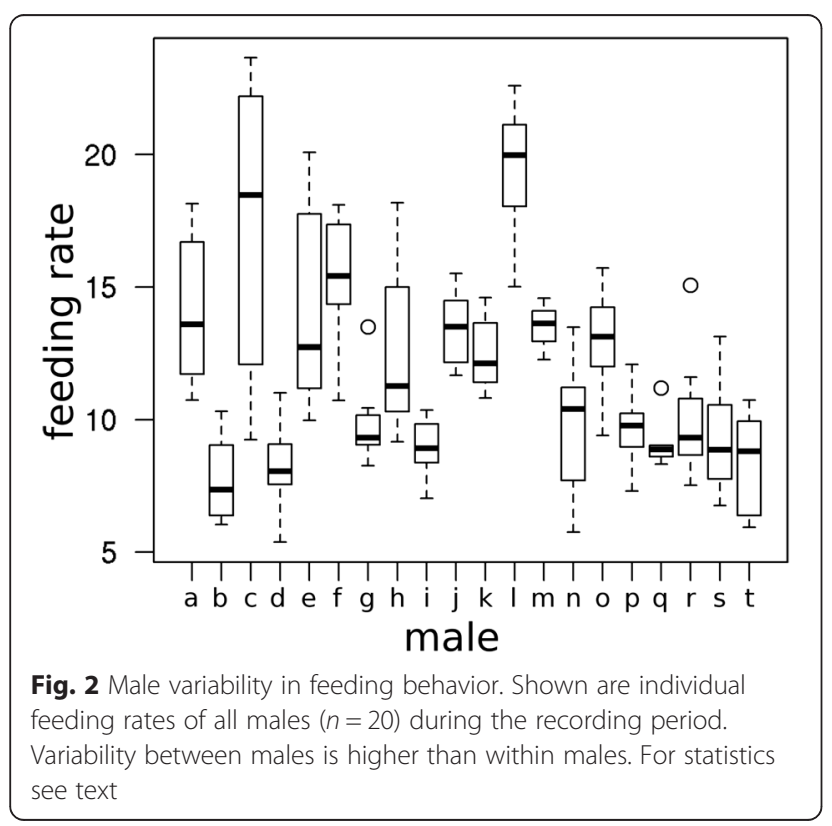

Additional file 1 for details on statistics and Additional file 1: Figures S4-S7). Thus, males with a more ordered singing style (i.e. male who repeatedly sang the same sequential order of song types indicated by higher average shortest path values) and more complex song repertoires (indicated by larger buzz, whistle and trill repertoire sizes) fed their chicks more often. The effects of all other song variables were reduced to zero by the LASSO algorithm. Besides song, the 'number of hatchlings' affected male feeding rates (regression coefficient: 0.43) whereas 'year' did not have an influence. With this subset of variables (shortest path length, buzz repertoire size, whistle repertoire size, trill repertoire size and number of hatchlings) we trained a support vector machine algorithm to test the combinatory predictive power of the variables. We found that the performance of the support vector machine was very good since the predicted feeding rates by the algorithm were highly correlated with the actual feeding rates observed in the field (Spearman rank correlation, $n=20, r=0.54, P=0.014$; see Fig. 3 ). Thus, feeding rates of males can be reliably predicted based on four combined song measures plus number of hatchlings.

\section{Discussion}

Our study confirmed previous observations that male nightingales considerably contribute to chick feeding

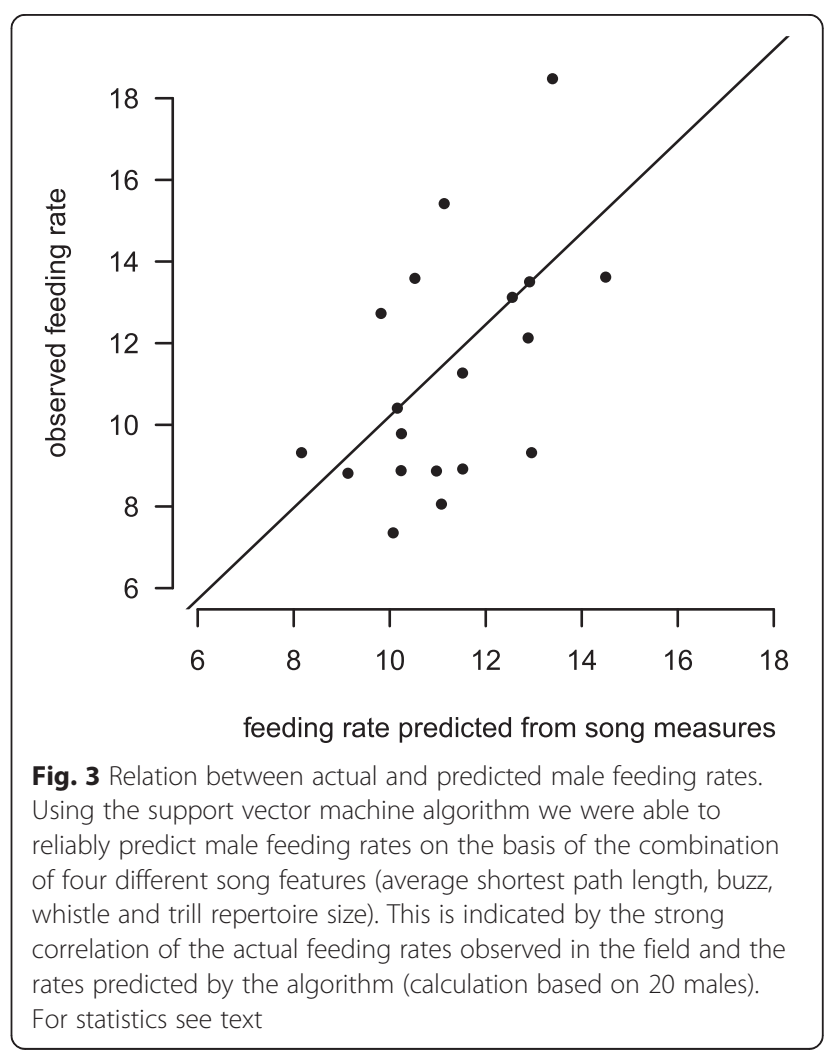


with large differences between individual males. These differences in male feeding effort were related to several features of male nocturnal song. When analyzing which song features reliably predict male parenting abilities we found that male feeding effort can be assessed on the basis of the combination of four song measures, namely song orderliness, buzz, whistle and trill repertoire size. More specifically, males that sang their song sequences more ordered and sang many different buzz, whistle as well as trill song types contributed more to chick feeding.

Our study provides the first thorough quantification of male feeding effort in nightingales including exemplary results on relative feeding contributions of both parents. Our results on male feeding behavior fit well the described pattern that in socially monogamous and monomorphic species male parental care is common, whereas reduced male care, or its absence, is often correlated with polygyny and with sexual dimorphism in birds $[6$, 53]. Most interestingly, we found that the extent of future paternal effort is advertised by male nocturnal song prior to pair formation. Evidence from the literature for this specific indicator function of song is still rare, especially for species with elaborate song (to compare: [25]). Also, we identified song characteristics that have not been described before to be related to paternal qualities in birds.

To the best of our knowledge, this is the first study reporting a relationship between sequential ordering of songs (here song orderliness) and paternal care in birds. Although the sequential organization of birdsong has been intensively studied ([54] and studies cited therein), there is only very scarce knowledge on the biological and adaptive value of song sequencing, e.g. $[47,55,56]$. In our study, the orderliness of male song sequencing indicated increased paternal investment. Given that song orderliness is also associated with male age [47], females choosing an orderly singing male might benefit from a male who signals viability and experience with the breeding grounds (factors significantly enhancing reproductive success in birds $[57,58])$ and his willingness to care for the offspring. Together these findings support the idea that the sequential ordering of birdsong carries relevant information during communication which may be directed to female listeners and thus, may have evolved by female choice [59].

In addition to song sequencing, measures of song complexity (here buzz, whistle and trill song repertoire size) were correlated with higher feeding rates in our study. A similar relationship between song complexity and male provisioning has so far only been reported for the sedge warbler [25]. In other studies, the value of mating with large repertoire singers has mostly been linked to indirect (i.e. genetic) benefits for females [29,60], or to other aspects of male quality (e.g. territory quality: $[61,62]$; body and health condition: [63, 64]; early condition: [30, 65]; age: [66]). For nightingales, the role of repertoire composition and size in interspecific contexts is not yet fully understood since we for example, lack evidence that females are attracted by more complex song. On the other hand, there is correlative data on the potential indicator function of large repertoires [35, 36] and playback studies showed that females prefer songs containing many different buzz or whistle songs $[37,40]$. Since in our study the number of different buzz, whistle and trill song types was highly correlated with repertoire size, it might be that females use the variety within song categories as a proxy for overall song complexity (i.e. repertoire size). Alternatively or additionally, the fine structure of either buzz, whistle and trill elements might encode information on male quality or motivation, and thus be relevant for females [67, 68]. To date, there is no direct evidence that the production of these elements is physically challenging for male nightingales. However, it was shown that males differ in the performance of these song structures, and that performance differences are related to male traits reflecting quality [37, 40,69]. Whether such performance measures predict paternal investment has not yet been investigated in songbirds, but there is accumulating evidence that even in large repertoire species the performance of fine-scale song structures is of adaptive value [70-72]. Although we cannot say what exact song features female nightingales finally use to assess males, it seems most likely that females use both, the quantity (i.e. repertoires) and quality (i.e. performance) of songs to assess a male's adequacy as a mating partner.

In socially monogamous taxa there are different models on the extent of paternal investment depending on self-attractiveness [73-75]. Although our data do not allow evaluating relative parental feeding effort in more detail (for example whether male attractiveness affected maternal effort, [76]) we found that better singers fed their offspring more often. This supports the 'good parent' hypothesis which predicts that an individual's attractiveness should reliably and positively indicate parental effort [9]. The quantification of further measures in the feeding context (such as for example female feeding contributions and chick mass or chick growth) will allow to draw a more detailed picture on the complex relationships between singing and parental investment in nightingales. With the method applied (support vector machine algorithm) we were able to identify four song parameters that gave strong predictive power for male feeding effort. This strategy (combinatory usage of different song features) might be also highly adaptive for 
females especially when the evaluation of single parameters might be time consuming (e.g. assessment of full repertoires), or is hindered or not possible (e.g. song structures especially prone to attenuation and degradation). The integration of multiple (vocal) cues might therefore enhance accurate and fast assessment of males and may thus be a prerequisite for successful reproduction $[77,78]$. This seems particularly feasible in species that have evolved complex vocal signal systems such as the nightingale where signals may contain multiple messages for different receivers [79].

\section{Conclusions}

We conclude that different aspects of male nightingale song honestly advertise direct fitness benefits to females. Here, measures of song complexity and song sequencing reliably predict paternal investment and thus might be important for female mating decisions. We suggest that, during mate choice, female nightingales rely on multiple song cues to quickly gather information about signaller quality.

\section{Methods}

\section{Study site and subjects}

The study was carried out on a population of nightingales in the Golmer Luch, Potsdam, Germany (52.4', $\left.12.97^{\circ}\right)$. Since 2009 , males have been monitored, banded and recorded in this area (see $[40,80]$ for details on breeding site and data acquisition). For the present study, subjects were 20 resident males (identifiable by unique color ring combinations) with established territories between 2010 and 2012 (each male was only sampled once). Males were regularly observed in their territories to confirm male identity and male pairing status throughout the breeding season. Nocturnal singing was recorded early in the breeding season when males were most probably still unpaired since males cease nocturnal song after pair formation [81]. Nests were located by observing nest related activities such as nest building, emission of alarm calls or feeding flights. We documented chick development (chick measurements and photos) within nests to estimate chick age \pm one day by comparing chick development to reference nests with known hatching date.

\section{Song analyses}

High quality recordings of nocturnal song (1130 pm$0300 \mathrm{am}$ ) were used for analyses. Song was recorded in 3-10 m distance of a singing male with a Sennheiser ME66/K6 directional microphone which was connected to a portable Marantz PMD-660 Compact Digital Recorder. All sound analyses were conducted with the software Avisoft SASlab Pro 4.52 (R. Specht, Berlin, Germany). Recordings were down-sampled to
$22.05 \mathrm{kHz}$, high pass filtered $(0.8 \mathrm{kHz}$, Butterworth) and amplitude normalized to $75 \%$. First, we determined repertoire sizes of all males via visual inspection of 533 consecutive songs, equalling approximately $1 \mathrm{~h}$ of singing, which has been proven to result in saturated repertoire curves (for details see [34, 35, 44]. Since nightingale song types have been assigned to song categories (e.g. buzz songs [37], trill songs [38] and whistle songs [39]), we further analyzed repertoire composition by determining how many different types occurred within each category (i.e. determination of whistle, trill and buzz song repertoire) and how often songs of these categories were sung (i.e. whistle, trill and buzz song occurrence irrespective of type, see also Table 1 and Fig. 1 for definitions and song examples). We also determined the degree of song orderliness using network analysis, where song sequences are translated into networks of song types as nodes with song transitions as connectors (following [47]). We calculated two network measures that have been shown to be particularly well suited to describe the sequential order of nightingale singing (i.e. with large repertoires and complex rules of song retrieval): average shortest path length and transitivity (for details on procedure see [47]). Average shortest path length is sensitive to long linear transitions of songs and transitivity refers to the interconnectivity of songs in sequential proximity [47] (Table 1).

\section{Male feeding}

In a pilot study on nestling provisioning in nightingales (conducted in 2008 and 2009), we obtained video recordings (recording time: $\sim 2 \mathrm{~h}$ per nest) from four nests during the late nestling phase (chicks older than eight days). Videos were analyzed to describe male feeding effort with special focus on the relative contribution of both parents to chick feeding. In all nests, male and female birds were distinguishable by colored leg rings.

Between 2010 and 2012 we used radio frequency identification (RFID) technology to record male visits to the nest (Assion Electronic, Niederkassel, Germany). To do so, a passive micro transponder $(\varnothing 2.2 \mathrm{~mm} \times$ $12 \mathrm{~mm}<0.1 \mathrm{~g}$ ) was glued to one of the plastic rings which were fitted to a male's leg during bird banding. The RFID device consisted of a data-logging device (LID-650 decoder, Assion Electronic) which was connected to a circular antenna $(\varnothing 120 \mathrm{~mm})$ and powered by an energy supply module (Assion Electronic). The antenna was positioned around the upper rim of the nest and the other equipment was placed on the ground nearby and covered with plant material not to distract the birds or attract the attention of predators. When a focal male approached the antenna $(<10 \mathrm{~cm})$, arrivals and departures were registered and saved exact 
Table 1 Overview on nightingale song measures

\begin{tabular}{|c|c|c|c|}
\hline Measure & Definition & Mean \pm SD & CV \\
\hline Repertoire size & Number of different song types & $181 \pm 35$ & 0.19 \\
\hline Whistle repertoire size & Number of whistle song types in the repertoire & $28 \pm 5$ & 0.18 \\
\hline Whistle song occurrence & Number of whistle songs (independent of types) in the song sample & $74 \pm 17$ & 0.23 \\
\hline Trill repertoire size & Number of trill song types in the repertoire & $20 \pm 4$ & 0.2 \\
\hline Trill song occurrence & Number of trill songs in the song sample & $64 \pm 10$ & 0.15 \\
\hline Buzz repertoire size & Number of buzz song types in the repertoire & $5 \pm 1$ & 0.33 \\
\hline Buzz song occurrence & Number of buzz songs in the song sample & $14 \pm 4$ & 0.3 \\
\hline Shortest path & Network measure: the path connecting two nodes with the minimal number of nodes in between & $4.66 \pm 0.84$ & 0.18 \\
\hline Transitivity & $\begin{array}{l}\text { Network measure: a measure for the probability that adjacent nodes of a given node are connected } \\
\text { as well }\end{array}$ & $0.18 \pm 0.03$ & 0.17 \\
\hline
\end{tabular}

Name, description, and mean values for song features under study. All measures refer to song samples of 533 consecutive songs. Mean values are shown for 20 males. Both network measures were calculated and then averaged for all possible nodes or pairs of nodes in a network

to the second. From this we calculated male visiting rate (number of visits/h). Since this method provided data on male visits to the nest, but not on actual provisioning, we compared the RFID data with data from a simultaneous video recording for one exemplary nest to validate the accuracy of the automated monitoring system and the relevance of the measure obtained. We found that RFID data correlated well with male nest attendance in the video recording and that the male brought food whenever he approached the nest (comparison of 17 nest visits in $\sim 80 \mathrm{~min}$ ). Thus, we concluded that male visiting rate was a good proxy for male feeding rate.

The RFID system collected data on male feeding behavior continuously from dusk till dawn registering all male nest visits during this time for several days between days 5 to 12 of chick age (note that not all males were sampled during the same nestling stages and males differed in total recording time; for more information and original data on male feeding efforts across daytimes and several nestling stages see Additional file 1: Figure S1-S3). For the analyses on the relationships between male feeding behavior and male song we only used data from the morning (feeding rate from $1^{\text {st }}$ nest visit in the morning until $10 \mathrm{am}$ ) and evening (feeding rate from $6 \mathrm{pm}$ until last nest visit in the evening) hours since these might be the biologically most critical periods due to feeding breaks during night. As a composite measure of feeding effort per male, we calculated the median of these rates for each male.

\section{Statistics}

All data were analyzed using $\mathrm{R}$ ( $\mathrm{R}$ Development Core Team, v. 3.1.1; [82]) and statistical significance was set at $P \leq 0.05$ (two-tailed).

To investigate the variability of feeding rates among males we calculated an analysis of variance (ANOVA). Next, we were interested in the identification of candidate song features that might be useful in predicting later parental investment of males. In a first step of analysis we reduced the number of song variables potentially related to male feeding rate by using the least absolute shrinkage and selection operator (LASSO) as implemented in the $\mathrm{R}$ package 'glmnet' [83]. We included feeding rate as response measure and the nine song measures (see Table 1) as fixed factors. Since it has been shown that feeding rates vary with brood size (e.g. [84, 85]) and might change between years (e.g. $[86,87])$, we included 'number of hatchlings' and 'year of study' as further factors to account for possible effects of confounding variables. Next, we investigated if the song features and other variables identified by the LASSO method can be used to predict male feeding rates. To do so, we used all variables of the reduced data set to train a support vector machine algorithm as implemented in the R package 'e1071' [88]. The training was performed as follows: we excluded one individual and trained the support vector machine with the measures of the remaining 19 males and predicted a feeding rate for the excluded individual from this data. This procedure was repeated until each of the 20 males was excluded and his feeding rate was predicted. To finally estimate the performance of the support vector machine we compared the predicted feeding rates with the actually observed feeding rates by calculating a Spearman rank correlation. To investigate the influence of each single song variable of the reduced data set in more detail, we additionally calculated Spearman correlations between song variables and male feeding rate (see also Additional file 1 for detailed results).

\section{Additional file}

Additional file 1: Supplementary data. The supplementary data include more detailed information on methods and results of song analysis and feeding behavior. 


\section{Abbreviations}

RFID: Radio frequency identification; SD: Standard deviation.

\section{Competing interests}

The authors declare that they have no competing interests.

\section{Authors' contributions}

CB and SK conceived the study. CB conducted the experiments, collected and analyzed the data. MW conducted most of the statistical analysis. CB wrote the manuscript. SK and MW constantly gave feedback on data analysis and on the manuscript. All authors read and approved the final manuscript.

\section{Acknowledgements}

We followed the Guidelines for the Use of Animals in Research and all experiments comply with the current laws of Germany. Bird banding was granted by the Landesumweltamt Brandenburg on behalf of the Vogelwarte Hiddensee. Many thanks to Christina Teutscher, Julia Stremel, Veronica Aponte, Ansgar Thode and Sarah Kiefer for assistance in the field, and Denise Bock and Jenny Noack for help with the video analysis. CB was funded by Berlin Funding for Graduates (Elsa-Neumann-Stipendium des Landes Berlin).

\begin{abstract}
Author details
'Animal Behavior Group, Freie Universität Berlin, Takustraße 6, 14195 Berlin, Germany. ${ }^{2}$ Department of Exposition, Unit Epidemiology, Statistics and Mathematical Modelling, Federal Institute for Risk Assessment (BfR), Max-Dohrn-Straße 8-10, 10589 Berlin, Germany. ${ }^{3}$ Chair of Zoology, Technische Universität München, Liesel-Beckmann-Str. 4, 85354 Freising, Germany.
\end{abstract}

Received: 5 January 2015 Accepted: 26 May 2015

Published online: 18 June 2015

\section{References}

1. Trivers RL. Parental investment and sexual selection. In: Campbell B, editor. Sexual selection and the descent of man. Chicago: Aldine Press; 1972. p. 136-79.

2. Reynolds JD. Animal breeding systems. Trends Ecol Evol. 1996;11:68-72.

3. Andersson MB. Sexual selection. Princeton: Princeton University Press; 1994

4. Kokko H, Brooks R, Jennions MD, Morley J. The evolution of mate choice and mating biases. P Roy Soc Lond B Bio. 2003;270:653-64.

5. Cockburn A. Prevalence of different modes of parental care in birds. P Roy Soc Lond B Bio. 2006:273:1375-83.

6. Ketterson ED, Nolan Jr V. Male parental behavior in birds. Ann Rev Ecol Syst. 1994;25:601-28.

7. Davies NB. Dunnock behaviour and social evolution. Oxford: Oxford University Press; 1992.

8. Møller AP, Thornhill R. Male parental care, differential parental investment by females and sexual selection. Anim Behav. 1998;55:1507-15.

9. Hoelzer GA. The good parent process of sexual selection. Anim Behav. 1980;38:1067-78

10. Møller AP, Jennions M. How important are direct fitness benefits of sexual selection? Naturwissenschaften. 2001:88:401-15.

11. Iwasa Y, Pomiankowski A. Good parent and good genes models of handicap evolution. J Theor Biol. 1999:200:97-109.

12. Zahavi A. Mate selection - a selection for a handicap. J Theor Biol. 1975:53:205-14.

13. Jennions MD, Møller AP, Petrie M. Sexually selected traits and adult survival: a meta-analysis. Q Rev Biol. 2001;76:3-36.

14. Hill GE. Plumage coloration is a sexually selected indicator of male quality. Nature. 1991:350:337-9.

15. Palokangas $P$, Korpimäki E, Hakkarainen H, Huhta E, Tolonen P, Alatalo RV. Female kestrels gain reproductive success by choosing brightly ornamented males. Anim Behav. 1994:47:443-8.

16. Nisbet ICT. Courtship-feeding, egg-size and breeding success in common terns. Nature. 1973:241:141-2

17. Knapp RA, Kovach JT. Courtship as an honest indicator of male parental quality in the bicolor damselfish, Stegastes partitus. Behav Ecol. 1991;2:295-300.

18. Moreno J, Soler M, Møller AP, Linden M. The function of stone carrying in the black wheatear, Oenanthe leucura. Anim Behav. 1994;47:1297-309.
19. Green DJ, Krebs EA. Courtship feeding in Ospreys Pandion haliaetus: a criterion for mate assessment? Ibis. 1995;137:35-43.

20. Catchpole CK, Slater PJB. Bird Song: Biological Themes and Variations. 2nd ed. New York: Cambridge University Press; 2008.

21. Greig-Smith PW. Song-rates and parental care by individual male stonechats (saxicola torquata). Anim Behav. 1982;30:245-52.

22. Hofstad E, Espmark Y, Moksnes A, Haugan T, Ingebrigtsen M. The relationship between song performance and male quality in snow buntings (Plectrophenax nivalis). Can J Zool. 2002;80:524-31.

23. Welling PP, Rytkönen SO, Koivula KT, Orell MI. Song rate correlates with paternal care and survival in willow tits: Advertisement of male quality? Behaviour. 1997;134:891-904.

24. Halupka K, Borowiec M. Male whitethroats, Sylvia communis, advertise their future contribution to parental care. Behaviour. 2006;143:1-14.

25. Buchanan $\mathrm{KL}$, Catchpole CK. Song as an indicator of male parental effort in the sedge warbler. P Roy Soc Lond B Bio. 2000;267:321-6.

26. Mountjoy DJ, Lemon RE. Male song complexity and parental care in the European starling. Behaviour. 1997;134:661-75.

27. Rinden H, Lampe HM, Slagsvold T, Espmark YO. Song quality does not indicate male parental abilities in the pied flycatcher Ficedula hypoleuca. Behaviour. 2000;137:809-23.

28. Dolby AS, Clarkson CE, Haas ET, Miller JK, Havens LE, Cox BK. Do song-phrase production rate and song versatility honestly communicate male parental quality in the Gray Catbird? J Field Ornithol. 2005;76:287-92.

29. Hasselquist D, Bensch S, von Schantz T. Correlation between male song repertoire, extra-pair paternity and offspring survival in the great reed warbler. Nature. 1996:381:229-32.

30. Nowicki S, Hasselquist D, Bensch S, Peters S. Nestling growth and song repertoire size in great reed warblers: evidence for song learning as an indicator mechanism in mate choice. P Roy Soc Lond B Bio. 2000;267:2419-24.

31. Buchanan $K L$, Leitner $S$, Spencer KA, Goldsmith AR, Catchpole CK. Developmental stress selectively affects the song control nucleus HVC in the zebra finch. P Roy Soc Lond B Bio. 2004;271:2381-6.

32. Horstkotte E. Untersuchungen zur Brutbiologie und Ethologie der Nachtigall (Luscinia megarhynchos Brehm). Berichte des naturwissenschaftlichen Vereins Bielefeld u. Umgebung. 1965;17:67-145.

33. Glutz von Blotzheim UN. Handbuch der Vögel Mitteleuropas. Wiesbaden: AULA-Verlag; 1989

34. Kipper S, Mundry R, Hultsch H, Todt D. Long-term persistence of song performance rules in nightingales (Luscinia megarhynchos): a longitudinal field study on repertoire size and composition. Behaviour. 2004;141:371-90.

35. Kipper S, Mundry R, Sommer C, Hultsch H, Todt D. Song repertoire size is correlated with body measures and arrival date in common nightingales (Luscinia megarhynchos). Anim Behav. 2006;71:211-7.

36. Kiefer S, Spiess A, Kipper S, Mundry R, Sommer C, Hultsch H, et al. First-year common nightingales (Iuscinia megarhynchos) have smaller song-type repertoire sizes than older males. Ethology. 2006:112:1217-24.

37. Weiss M, Kiefer S, Kipper S. Buzzwords in females' ears? The use of buzz songs in the communication of nightingales (Luscinia megarhynchos). PLoS One. 2012;7:e45057.

38. Kunc HP, Amrhein V, Naguib M. Vocal interactions in nightingales, Luscinia megarhynchos: more aggressive males have higher pairing success. Anim Behav. 2006;72:25-30.

39. Naguib M, Mundry R, Hultsch H, Todt D. Responses to playback of whistle songs and normal songs in male nightingales: effects of song category, whistle pitch, and distance. Behav Ecol Sociobiol. 2002;52:216-23.

40. Bartsch C, Hultsch H, Scharff C, Kipper S. What is the whistle all about? A study on whistle songs, related male characteristics, and female song preferences in common nightingales. 2014; accepted manuscript.

41. Hultsch H, Todt D. Memorization and reproduction of songs in nightingales (Luscinia megarhynchos): evidence for package formation. J Comp Physiol A. 1989:165:197-203.

42. Hultsch $\mathrm{H}$. Early experience can modify singing styles: evidence from experiments with nightingales, Luscinia megarhynchos. Anim Behav. 1991;42:883-9.

43. Geberzahn N, Hultsch H, Todt D. Latent song type memories are accessible through auditory stimulation in a hand-reared songbird. Anim Behav. 2002;64:783-90.

44. Kiefer S, Sommer C, Scharff C, Kipper S, Mundry R. Tuning towards tomorrow? Common nightingales Luscinia megarhynchos change and increase their song repertoires from the first to the second breeding season. J Avian Biol. 2009:40:231-6. 
45. Kiefer S, Sommer C, Scharff C, Kipper S. Singing the popular songs? Nightingales share more song types with their breeding population in their second season than in their first. Ethology. 2010;116:619-26.

46. Weiss M. From syntax to details: Organisational principles and information encoding in the singing of nightingales (Luscinia megarhynchos). In: PhD thesis. Berlin: Free University of Berlin, Animal Behavior Group; 2013.

47. Weiss M, Hultsch H, Adam I, Scharff C, Kipper S. The use of network analysis to study complex animal communication systems: a study on nightingale song. P Roy Soc Lond B Bio. 2014;281:20140460.

48. Hultsch $\mathrm{H}$. Beziehungen zwischen Struktur, zeitlicher Variabilität und sozialem Einsatz des Gesangs der Nachtigall (Luscinia megarhynchos B.). In: PhD thesis. Berlin: Free University of Berlin; 1980.

49. Kunc HP, Amrhein V, Naguib M. Seasonal variation in dawn song characteristics in the common nightingale. Anim Behav. 2005;70:1265-71.

50. Kunc HP, Amrhein V, Naguib M. Acoustic features of song categories and their possible implications for communication in the common nightingale (Luscinia megarhynchos). Behaviour. 2005;142:1083-98.

51. Sprau P, Roth $T$, Schmidt R, Amrhein V, Naguib M. Communication across territory boundaries: distance-dependent responses in nightingales. Behav Ecol. 2010;21:1011-7.

52. Sprau P, Schmidt R, Roth T, Amrhein V, Naguib M. Effects of rapid broadband trills on responses to song overlapping in nightingales. Ethology. 2010;116:300-8.

53. Kokko H. Cuckoldry and the stability of biparental care. Ecol Lett. 1999;2:247-55

54. Berwick RC, Okanoya K, Beckers GJ, Bolhuis JJ. Songs to syntax: the linguistics of birdsong. Trends Cogn Sci. 2011;15:113-21.

55. Okanoya K. The Bengalese finch: a window on the behavioral neurobiology of birdsong syntax. Ann NY Acad Sci. 2004;1016:724-35.

56. Holveck MJ, de Castro ACV, Lachlan RF, ten Cate C, Riebel K. Accuracy of song syntax learning and singing consistency signal early condition in zebra finches. Behav Ecol. 2008;19:1267-81.

57. Forslund P, Pärt T. Age and reproduction in birds - hypotheses and tests. Trends Ecol Evol. 1995;10:374-8.

58. Bradley RJ, Safran RJ. Conceptual revision and synthesis of proximate factors associated with age-related improvement in reproduction. Ethology. 2014;120:411-26.

59. Sasahara K, Ikegami T. Evolution of birdsong syntax by interjection communication. Artif Life. 2007;13:259-77.

60. Reid J, Arcese P, Cassidy AE, Marr A, Smith JM, Keller L. Hamilton and Zuk meet heterozygosity? Song repertoire size indicates inbreeding and immunity in song sparrows (Melospiza melodia). P Roy Soc Lond B Bio. 2005;272:481-7.

61. Krebs JR. Song and territory defense in the Great Tit. In: Stonehouse B, Perrins CM, editors. Evolutionary ecology. London: Macmillan; 1977. p. 47-62.

62. Catchpole CK. Song repertoires and reproductive success in the great reed warbler Acrocephalus arundinaceus. Behav Ecol Sociobiol. 1986;19:439-45.

63. Lampe HM, Espmark YO. Song structure reflects male quality in pied flycatchers, Ficedula hypoleuca. Anim Behav. 1994;47:869-76.

64. Buchanan KL, Catchpole CK, Lewis JW, Lodge A. Song as an indicator of parasitism in the sedge warbler. Anim Behav. 1999;57:307-14.

65. Spencer KA, Buchanan KL, Goldsmith AR, Catchpole CK. Developmental stress, social rank and song complexity in the European starling (Sturnus vulgaris). Biol Lett. 2004;271:121-3.

66. Kipper S, Kiefer S. Age-related changes in birds' singing styles: on fresh tunes and fading voices? Adv Stud Behav. 2010;41:77-118.

67. Sakata JT, Vehrencamp SL. Integrating perspectives on vocal performance and consistency. J Exp Biol. 2012;215:201-9.

68. Wilson DR, Bitton PP, Podos J, Mennill DJ. Uneven sampling and the analysis of vocal performance constraints. Am Nat. 2014;183:214-28.

69. Sprau P, Roth T, Amrhein V, Naguib M. The predictive value of trill performance in a large repertoire songbird, the nightingale Luscinia megarhynchos. J Avian Biol. 2013;44:567-74.

70. Drăgănoiu TI, Nagle L, Kreutzer M. Directional female preference for an exaggerated male trait in canary (Serinus canaria) song. P Roy Soc Lond B Bio. 2002;269:2525-31.

71. Botero CA, Rossman RJ, Caro LM, Stenzler LM, Lovette IJ, de Kort SR, et al. Syllable type consistency is related to age, social status and reproductive success in the tropical mockingbird. Anim Behav. 2009;77:701-6.
72. Geberzahn N, Aubin T. Assessing vocal performance in complex birdsong: a novel approach. BMC Biol. 2014;12:58.

73. Burley N. Sexual selection for aesthetic traits in species with biparental care. Am Nat. 1986;127:415-45.

74. Gowaty PA. Reproductive compensation. J Evol Biol. 2008;21:1189-200.

75. Ratikainen II, Kokko H. Differential allocation and compensation: who deserves the silver spoon? Behav Ecol. 2009;21:195-200.

76. Pedro D, Ramos DM, Macedo RH. Attractive males are less than adequate dads in a multimodal signalling passerine. Anim Behav. 2015;102:109-17.

77. Gibson RM, Langen TA. How do animals choose their mates? Trends Ecol Evol. 1996;11:468-70.

78. Candolin U. The use of multiple cues in mate choice. Biol Rev. 2003;78:575-95.

79. Todt D, Naguib M. Vocal interactions in birds: the use of song as a model in communication. Adv Stud Behav. 2000;29:247-95.

80. Bartsch C, Wenchel R, Kaiser A, Kipper S. Singing onstage: female and male common nightingales eavesdrop on song type matching. Behav Ecol Sociobiol. 2014;68:1163-71.

81. Amrhein V, Korner P, Naguib M. Nocturnal and diurnal singing activity in the nightingale: correlations with mating status and breeding cycle. Anim Behav. 2002;64:939-44

82. $R$ : a language and environment for statistical computing. $R$ Foundation for Statistical Computing, Vienna, Austria; 2011.

83. Friedman J, Hastie T, Tibshirani R. Regularization Paths for Generalized Linear Models via Coordinate Descent. J Stat Softw. 2010;33:1-22.

84. Wright J, Cuthill I. Biparental care: short-term manipulation of partner contribution and brood size in the starling. Sturnus vulgaris Behav Ecol. 1990;1:116-24

85. Rytkönen S, Koivula K, Orell M. Patterns of per-brood and per-offspring provisioning efforts in the Willow Tit Parus montanus. J Avian Biol. 1996;27:21-30.

86. Lyon BE, Montgomerie RD, Hamilton LD. Male parental care and monogamy in snow buntings. Behav Ecol Sociobiol. 1987;20:377-82.

87. Weimerskirch $H$, Mougey $T$, Hindermeyer X. Foraging and provisioning strategies of black-browed albatrosses in relation to the requirements of the chick: natural variation and experimental study. Behav Ecol. 1997;8:635-43.

88. Meyer D. Support Vector Machines: The Interface to libsvm in package e1071. Available from http://cran.r-project.org/web/packages/e1071/. Technische Universität Wien; 2011.

\section{Submit your next manuscript to BioMed Central and take full advantage of:}

- Convenient online submission

- Thorough peer review

- No space constraints or color figure charges

- Immediate publication on acceptance

- Inclusion in PubMed, CAS, Scopus and Google Scholar

- Research which is freely available for redistribution 